\title{
The Influence of Indomethacin on the Autoregulatory Ability of the Cerebral Vascular Bed in the Newborn Lamb
}

\author{
FRANK VAN BEL, ROBERT J. M. KLAUTZ, PAUL STEENDIJK. INGER B. SCHIPPER. \\ DAVID F. TEITEL, AND JAN BAAN \\ Clinical Physiology! Lahoratory: Departments of Pediatrics and Cardiology: L'niversity Hospital Leiden. \\ Leiden. The Netherlands
}

\begin{abstract}
Prevention of hyperperfusion of the brain in the perinatal period has been thought to be an important mechanism by which indomethacin reduces the risk for severe periventricular-intraventricular hemorrhage. The present study investigated whether an indomethacin-induced enhancement of the upper limit of cerebral vascular autoregulatory ability in the neonate contributed to this reduction in cerebral blood flow. In seven anesthetized newborn lambs, we measured temporal blood flow velocity (TMFV) in the carotid artery over a wide range of mean aortic blood pressures (MABP) before and $30 \mathrm{~min}$ after an i.v. dose of $1 \mathrm{mg} / \mathrm{kg}$ indomethacin. TMFV in the carotid artery was used as an estimate for changes in cerebral blood flow. Stepwise changes in MABP of approximately $10 \mathrm{~mm} \mathrm{Hg}$ were achieved by progressive balloon occlusion of the thoracic aorta or by progressive bleeding. Multiple linear regression analysis of TMFV versus MABP, indomethacin, and the possible interactive effects confirmed that, at MABP values up to $86 \mathrm{~mm} \mathrm{Hg}$, indomethacin lowered TMFV of the carotid artery. Above $86 \mathrm{~mm} \mathrm{Hg}$, indomethacin reduced the slope of the TMFV-MABP relationship, indicating an improvement of the autoregulatory ability of the cerebral vascular bed. There was a significant interanimal variability. Thus, indomethacin may reduce the risk for PIVH by limiting cerebral blood flow, especially during increased cerebral perfusion pressures, which often occur after birth asphyxia. (Pediatr Res 34: 178-181, 1993)
\end{abstract}

\section{Abbreviations}

MABP, mean aortic blood pressure

PIVH, periventricular-intraventricular hemorrhage

TMFV, temporal mean flow velocity

Neonatal PIVH causes significant mortality and morbidity (1. 2). Birth asphyxia with subsequent prostaglandin-induced postasphytic hyperperfusion of the neonatal brain may be an important cause of PIVH $(3,4)$ and has generated interest in pharmacologic prevention studies. Indomethacin, a cyclooxygenase inhibitor, has been found to decrease the risk for PIVH when given within $12 \mathrm{~h}$ after birth (5-9). Indomethacin is thought to act by attenuating brain blood flow and by modulating the

Received January 31, 1992: accepted March I, 1993.

Correspondence and reprint requests: F. van Bel, M.D., Department of Pediatrics. Neonatal Unit, University Hospital Leiden, P. O. Box 9600, 2300 RC. Leiden. The Netherlands.

Supported in part by a grant from the Ghisela Thier Foundation. Leiden. The Netherlands (R.J.M.K.). vasodilatory effect of hypercapnia on cerebral resistance vessels (10,11). Recent reports $(12,13)$ also suggest that cyclooxygenase inhibitors enhance the autoregulatory ability of the neonatal cerebral vascular bed, which also may contribute to the decrease in the occurrence of PIVH.

We therefore investigated the influence of indomethacin on cerebral blood flow and especially on the upper limit of the autoregulatory ability of the cerebral vascular bed in the newborn lamb.

\section{MATERIAL AND METHODS}

Animal preparation. Surgical and experimental procedures used were reviewed and approved by the Committee on Animal Experiments at the University of Leiden and the scientific board of the Department of Pediatrics.

Ten newborn lambs with weights ranging from 3.5 to $5.9 \mathrm{~kg}$ (mean \pm SD: $4.7 \pm 0.7 \mathrm{~kg}$ ) and ages ranging from 2 to $11 \mathrm{~d}$ (mean \pm SD: $5.6 \pm 3.0 \mathrm{~d}$ ) were studied. Nine out of 10 animals were studied in the first wk of life. After premedication with ketamine hydrochloride ( $3 \mathrm{mg} / \mathrm{kg}$ i.v.). general anesthesia was maintained using continuous infusion of ketamine hydrochloride $(8-30 \mathrm{mg} / \mathrm{kg} / \mathrm{h})$, adjusted according to heart rate and blood pressure changes in response to external stimuli. After intubation, the lambs were ventilated with oxygen and air using a pressureregulated ventilator that was adjusted to maintain arterial $\mathrm{PO}_{2}$ and $\mathrm{PCO}_{2}$ in the normal range. Pancuronium $(0.2 \mathrm{mg} / \mathrm{kg}$ i.v. $)$ was administered for muscle relaxation. An i.v. infusion of $10 \%$ dextrose in $0.5 \mathrm{~N} \mathrm{NaCl}$ solution was maintained throughout the study at about $4 \mathrm{~mL} / \mathrm{kg} / \mathrm{h}$. $\mathrm{NaHCO}_{3}$ was supplemented if the arterial pH was lower than 7.26 .

Estimation of cerebral blood flow. The left carotid artery was insonated to obtain its Doppler-derived velocity wave form. After exposing the carotid artery in the neck, an appropriately sized $20-\mathrm{MHz}$ Doppler flow probe was applied to fit around the vessel and connected to a range-gated pulsed Doppler flow meter (Crystal Biotech, Holliston, MA). The range-gate was adjusted to detect the highest possible velocity for subsequent determination of the optimal blood flow velocity wave form. TMFV of the carotid artery, expressed in $\mathrm{cm} / \mathrm{s}$, was used to estimate changes in actual cerebral blood flow (14).

Changes in cerebral perfusion pressure. In the right and left femoral arteries and veins, $6 \mathrm{~F}$ or $7 \mathrm{~F}$ self-sealing sheaths were placed using a percutaneous technique. In one femoral artery, a $5 \mathrm{~F}$ atrioseptostomy catheter (American Edwards Laboratories, Irvine. CA) was advanced to the midthoracic aorta. In the other femoral artery, a 5F micromanometer catheter (Millar Instruments. Houston, TX) was advanced into the thoracic aorta and situated proximal to the balloon catheter for measurement of instantaneous mean aortic pressure. Both femoral venous catheters were used for blood withdrawal and reperfusion and for 
administrating drugs. Cerebral perfusion pressure was increased by stepwise balloon occlusion of the aorta and decreased by stepwise bleeding (via a femoral vein).

Physiologic measurements. Arterial blood gases and $\mathrm{pH}$ were measured using a Corning $178 \mathrm{pH} /$ blood gas analyzer (Corning, Halstead, UK). Blood gases, pH, and hematocrit were determined at regular intervals and adjusted as necessary.

Study protocol. After completion of the surgical preparation, a 30-min period was allowed to achieve hemodynamic stability. During the control condition, MABP was increased in steps of approximately $10 \mathrm{~mm} \mathrm{Hg}$ by stepwise balloon occlusion, starting from baseline (baseline level I). After each step and during steady state, TMFV of the carotid artery was determined from the velocity wave form during 20 to 30 consecutive heart beats. After maximal aortic occlusion, the aortic balloon was released (baseline level II). Then, stepwise bleeding was executed in an attempt to lower MABP to a value near the assumed lower limit (40 to $45 \mathrm{~mm} \mathrm{Hg}$ ) of cerebral autoregulation $(15,16)$. Because we were especially interested in the action of indomethacin on the upper limit of cerebral autoregulation and because too-low perfusion pressures could disturb cerebral autoregulatory ability, we never decreased mean aortic pressure below $42 \mathrm{~mm} \mathrm{Hg}$. The blood was carefully reperfused afterwards, and after stabilization of the MABP, $1 \mathrm{mg} / \mathrm{kg}$ indomethacin was administered i.v. over $1 \mathrm{~min}$. After $30 \mathrm{~min}$ or after reaching hemodynamic stability, the procedure followed during the control condition was repeated (postindomethacin condition).

MABP as well as the blood flow velocity wave form of the carotid artery were continuously displayed on a memory oscilloscope (Gould OS 4100, Hainault, UK). The blood flow velocity wave form of the carotid artery, ECG, and aortic pressure were digitized with a sample frequency of $200 \mathrm{~Hz}$ and stored on hard disk using a personal computer.

Statistical analysis. If cerebral autoregulation is present, the relationship between cerebral perfusion pressure and cerebral blood flow is expected to be nonlinear over the full range of perfusion pressures, but fairly linear below the lower limit, between the lower and upper limits, and above the upper limit of the autoregulatory range. As we were interested in the upperlimit range of the autoregulation, we defined two ranges of MABP in which we investigated the relation between TMFV and MABP separately, using a linear regression model: 1) Between MABP values of about $45 \mathrm{~mm} \mathrm{Hg}$ and the upper limit of cerebral autoregulation, and 2) at MABP values above this upper limit. In the control condition, the upper limit breakpoint of the autoregulatory plateau was determined mathematically by repetitively fitting a linear regression model through the data (TMFVMABP relationship) above and below a test point using different test points in the range from 75 to $95 \mathrm{~mm} \mathrm{Hg}$. To correct for interanimal variability, we included dummy variables to code the different animals (see below). The breakpoint was defined as the test point where the sum of the residuals from the two fits was minimal $(16,17)$.

To investigate whether indomethacin had a significant effect on the autoregulatory ability of the cerebral vascular bed of the newborn lamb, we analyzed the TMFV-MABP relationship with and without indomethacin over the two above-defined pressure ranges. We used a multiple linear regression model with dummy variables in both above-defined ranges, and the following regression equation:

$$
Y=b_{o}+b_{M} M A B P+b_{i} I+b_{M \cdot I} M A B P \cdot I+\sum_{k=1}^{6} b_{l_{k}} L_{k}
$$

where $\mathrm{Y}$ is the dependent variable (TMFV), and $b_{o}$ is its overall mean value over all conditions and all animals. MABP is the first independent variable, and its coefficient $b_{M}$ defines the slope of the pressure-flow relationship, which is used as indicator of autoregulatory ability. If this parameter is not significant, there is strong autoregulation, because flow does not depend on perfusion pressure. There is one drug (dummy) variable, $I$, repre- senting the control condition (value 0 ) or the postindomethacin condition (value 1 ). The coefficient $b_{i}$ indicates the independent effect of indomethacin on TMFV, thus affecting the intercept of the TMFV-MABP relationship. The third independent variable is an interaction variable, MABP.I, representing the interactive effect of indomethacin and MABP on the TMFV. The coefficient $b_{M .1}$ indicates, therefore, the effect of indomethacin on the slope of the TMFV-MABP relationship. Finally, to correct for interanimal variability, six dummy variables $\left(\mathrm{L}_{1}-\mathrm{L}_{6}\right)$ were introduced for the seven animals included in this analysis (18). To determine the statistical significance of any variable, an $F$ test was performed by dividing the mean square of that variable by the mean square residual.

Differences in $\mathrm{pH}, \mathrm{PCO}_{2}$ and $\mathrm{PO}_{2}, \mathrm{MABP}$, and hematocrit among the four baseline values (baseline I and II during the control condition, baseline I and II during the postindomethacin condition) were investigated by analysis of variance for repeated measurements followed by the Newman-Keuls test if statistically significant differences were obtained. Statistical significance was assumed for $p<0.05$. Groups of data are summarized as mean $\pm 1 \mathrm{SD}$.

\section{RESULTS}

Each measurement was performed after steady state had been reached, which, on the average, took 3 to $5 \mathrm{~min}$ after every change in aortic pressure. We sampled the TMFV-wave form and aortic pressure for $40 \mathrm{~s}$ and used representative recordings for further analysis. In seven of the 10 animals, we were able to obtain a sufficiently large range of MABP-values from near the presumed lower limit of 40 to $45 \mathrm{~mm} \mathrm{Hg}$ to well above the calculated upper limit (see below) of cerebral autoregulation in newborn lambs. Only the results obtained from these seven lambs were used for statistical evaluation as described in this section. Immediately after indomethacin administration. there was a sharp rise of MABP in all cases, but in all animals, MABP decreased within 30 min to values not significantly different from those measured during the baseline conditions before indomethacin. Also, no differences were found between baseline values of other pertinent clinical variables in any baseline condition (Table $1)$.

Figure I shows the plot of all individual values of TMFV against MABP. The calculated upper limit of the autoregulatory ability of the cerebral vascular bed of the newborn lamb appeared to be $86 \mathrm{~mm} \mathrm{Hg}$, which was in accordance with data in literature $(15,16)$. The test points used to arrive at this value ranged from 75 to $95 \mathrm{~mm} \mathrm{Hg}$.

The values of MABP in which cerebral autoregulation was supposed to be operative, ranged from 42 to $86 \mathrm{~mm} \mathrm{Hg}$ (upper limit indicated by arrow in Fig. 1). Using the multiple linear regression model, we found a small but significant effect of MABP on TMFV $\left(b_{M}: 0.23 \mathrm{~cm} \cdot \mathrm{s}^{-1} / \mathrm{mm} \mathrm{Hg}\right)$ in this range and a slope whose value was not significantly affected by indomethacin (b $b_{M}$ : $:$ NS). In contrast, indomethacin did affect the intercept of the relationship significantly (from 15.85 to $1.04 \mathrm{~cm} \cdot \mathrm{s}^{-1}$ ), indicating that indomethacin had a pressure-independent effect on flow $\left(b_{1}:-14.8 \mathrm{~cm} \cdot \mathrm{s}^{-1}\right)$, decreasing it for any given pressure over the autoregulatory range. The results are summarized in Table

Table 1. Clinical data (means $\pm 1 S D$ ) at baseline levels I and II before and after indomethacin administration of seven newborn lambs

\begin{tabular}{lccccc}
\hline & \multicolumn{2}{c}{ Before indomethacin } & & \multicolumn{2}{c}{ After indomethacin } \\
\cline { 2 - 3 } \cline { 5 - 6 } & Baseline I & Baseline II & & Baseline I & Baseline II \\
\hline $\mathrm{pH}$ & $7.35 \pm 0.05$ & $7.38 \pm 0.07$ & & $7.34 \pm 0.04$ & $7.34 \pm 0.07$ \\
$\mathrm{PCO}_{2}(\mathrm{kPa})$ & $4.6 \pm 0.8$ & $4.5 \pm 0.9$ & & $5.1 \pm 1.0$ & $5.0 \pm 0.7$ \\
$\mathrm{PO}_{2}(\mathrm{kPa})$ & $13.3 \pm 3.4$ & $12.1 \pm 1.9$ & & $12.7 \pm 4.2$ & $11.1 \pm 3.9$ \\
$\mathrm{MABP}(\mathrm{mm} \mathrm{Hg})$ & $65 \pm 7$ & $63 \pm 10$ & & $72 \pm 13$ & $69 \pm 18$ \\
Hematocrit (L/L) & $39 \pm 2$ & $41 \pm 3$ & & $43 \pm 2$ & $41 \pm 2$ \\
\hline
\end{tabular}




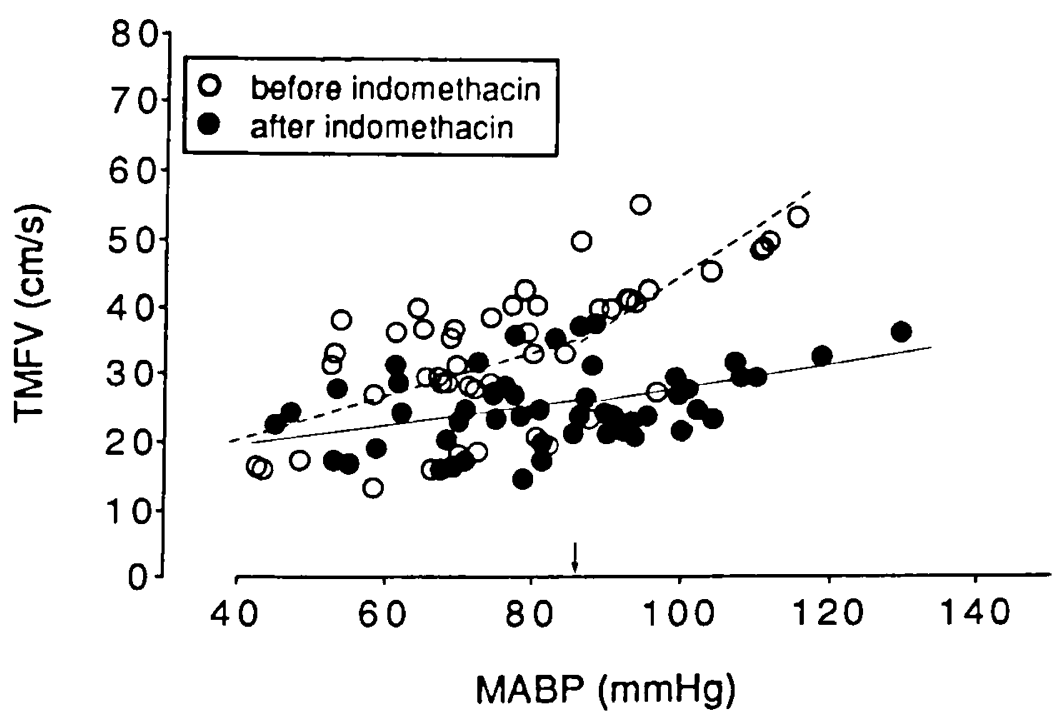

Fig. 1. Individual values of the TMFV as a function of MABP before and after indomethacin administration. The lines represent the regression lines of the TMFV-MABP relationship before (- - ) and after (-) indomethacin administration over the pressure ranges below and above the highest MABP value ( $86 \mathrm{~mm} \mathrm{Hg}$; arrow) at which cerebral autoregulation is supposed to be operative, respectively. For explanation about how this point was determined, see text.

Table 2. Results of multiple linear regression analysis of TMFV (dependent variable) on two independent variables: $M A B P\left(b_{M}\right)$ and drug variable $I$ (whose coefficient $b$, indicates independent effect of indomethacin on TMFV), and interaction variable MABP.I (whose coefficient $b_{m \cdot 1}$ indicates interactive effect of indomethacin on slope of TMFV-MABP relationship*

\begin{tabular}{|c|c|c|c|c|c|c|c|c|c|c|}
\hline & $b_{o}$ & $b_{M}$ & $b_{1}$ & $b_{M \cdot 1}$ & $\mathrm{LI}$ & $\mathrm{L} 2$ & L3 & L4 & L5 & L6 \\
\hline \multicolumn{11}{|c|}{$\mathrm{MABP}<87 \mathrm{~mm} \mathrm{Hg}$} \\
\hline b & 15.85 & 0.23 & -14.81 & 0.09 & 5.73 & 5.54 & -10.93 & -8.95 & -0.48 & -2.04 \\
\hline SEM & 4.09 & 0.04 & 3.18 & 0.05 & 1.21 & 1.44 & 1.42 & 1.20 & 1.10 & 1.19 \\
\hline & & $<0.0001$ & $<0.05$ & NS & \multicolumn{6}{|c|}{$<0.0001$} \\
\hline \multicolumn{11}{|c|}{$\mathrm{MABP}>86 \mathrm{~mm} \mathrm{Hg}$} \\
\hline $\mathrm{b}$ & -6.61 & 0.37 & 8.02 & -0.23 & 5.74 & 1.24 & -9.66 & -6.55 & -0.48 & -2.04 \\
\hline SEM & 10.54 & 0.08 & 8.99 & 0.09 & 2.26 & 1.29 & 1.45 & 2.08 & 0.95 & 0.94 \\
\hline$p$ & & $<0.0001$ & NS & $<0.05$ & \multicolumn{6}{|c|}{$<0.001$} \\
\hline
\end{tabular}

${ }^{*} b_{o}$ is the overall intercept. For correction of interanimal variability, six dummy variables for seven animals were introduced (L1-L6). This analysis was done for two ranges of pressure (MABP $<87 \mathrm{~mm} \mathrm{Hg}$ and MABP $>86 \mathrm{~mm} \mathrm{Hg}$ ). Their regression equations were statistically significant $(p<0.0001$ and $p<0.0001$, respectively).

2. Above $86 \mathrm{~mm} \mathrm{Hg}$ (Table 2), MABP had a larger effect on TMFV during the control condition $\left(b_{M}: 0.53 \mathrm{~cm} \cdot \mathrm{s}^{-1} / \mathrm{mm} \mathrm{Hg}\right.$ ). However, in this range, indomethacin did have a significant effect on the slope of the pressure-flow relationship $\left(b_{M .1}:-0.23\right.$ $\mathrm{cm} \cdot \mathrm{s}^{-1} / \mathrm{mm} \mathrm{Hg}$ ). This means that indomethacin reduced the slope of the TMFV-MABP relationship significantly from 0.37 to $0.14 \mathrm{~cm} \cdot \mathrm{s}^{-1} / \mathrm{mm} \mathrm{Hg}$. This reduction in slope is a reflection of an improvement of the autoregulatory ability: the autoregulatory range appears to be greatly expanded, as shown in Figure 1. Indomethacin had no significant pressure-independent-lowering effect on TMFV above $86 \mathrm{~mm} \mathrm{Hg}$. It is also clear from Table 2 that there is a significant interanimal variability in both investigated MABP ranges, which reflects the biologic variance.

After completion of the study, balloon catheter positions were checked. Moreover, in all animals, the ductus arteriosus appeared to be closed.

\section{DISCUSSION}

The present study shows that indomethacin decreases TMFV of the carotid artery and reduces the slope of the TMFV-MABP relationship at higher levels of MABP as compared with the control condition. Although reductions in TMFV may indicate reductions in actual cerebral blood flow, the simultaneous changes in blood pressure may induce autoregulatory alterations in the diameter of the vessel under investigation (i.e. the carotid artery), which will result in changes of the velocity wave form without changes in actual cerebral blood flow. Although the diameter of the carotid artery may change to some extent during changes in blood pressure, cerebral vascular resistance (if cerebral autoregulation is intact) will largely be controlled by the cerebral arterioles situated distal to the carotid arteries, whose diameters remain relatively unchanged $(14,19,20)$. We used the TMFV of the extracranially situated (common) carotid artery, which supplies the brain with only 50 to $70 \%$ of its total blood flow. However, an earlier study in newborn lambs has reported a close correlation between the extracranially measured carotid artery TMFV, using electromagnetic flow probes, and the Dopplerderived TMFV from an intracranially situated major artery using an artificial fontanel (21). That indomethacin should disturb this relation because of disproportional constriction of extracranially situated branches of the carotid artery, supplying muscle and skin, is not likely. Studies investigating the effect of indomethacin on the muscular arterial vascular bed have reported only a modest effect of indomethacin on the arteries and arterioles of the muscles $(22-24)$, contrary to the action of indomethacin on the resistance vessels in the brain. It is also not very likely that ketamine hydrochloride, used as anesthetic in our experiments, could have influenced the relation between TMFV of the carotid artery and true cerebral blood flow, because its cardiovascular effect is small and only transient (25). We therefore suggest that changes of the TMFV of the carotid artery can be used reliably as marker for changes in cerebral blood flow.

Several clinical studies have reported a decrease in the incidence of severe PIVH in the preterm baby after early indometh- 
acin treatment. The present study suggests that this lower incidence of PIVH may, at least partially, be caused by reduction of cerebral hyperemia by indomethacin: the enhancement of the autoregulatory ability of the neonatal cerebral vascular bed at high cerebral perfusion pressures may confine the hyperemia associated with asphyxia and hypercarbia at birth. Earlier experimental and clinical studies have demonstrated a relationship between hyperperfusion of the neonatal brain (26) and impaired autoregulation of the neonatal cerebral vascular bed (27) on the one hand and the occurrence of PIVH on the other hand. Indomethacin may abolish this process or, at least, limit its deleterious consequences.

We did find a small but significant relationship between TMFV and MABP in the autoregulatory range of MABP. In an ideally autoregulated bed, such a relationship should be absent. Possible mechanisms for its occurrence include the acute effects of instrumentation and/or anesthesia, but this has not previously been demonstrated. Moreover, the animals were all in good condition during the experiments. An alternative explanation may be that some measurements were obtained below the autoregulatory range; when we excluded the measurements made at MABP values below $45 \mathrm{~mm} \mathrm{Hg}$, the relationship indeed disappeared. Lastly, the presence of the relationship may be caused by some involvement of the extracerebral vascular bed, which is not autoregulated.

As stated earlier, we did not collect data at MABP values well below the supposed lower limit of cerebral autoregulation $(<40$ $\mathrm{mm} \mathrm{Hg}$ ) to determine whether indomethacin might affect cerebral blood flow below the autoregulatory range (28). Thus, it remains to be investigated whether indomethacin has a negative effect on cerebral blood flow (and metabolism) at lower cerebral perfusion pressures. Furthermore, it remains to be determined whether or not the proven ability of indomethacin to act as a protector against oxygen-free radical injury of the vessels in the neonatal brain $(29,30)$ may also be instrumental in the decrease of severe PIVH: birth asphyxia-related excessive free-radical activity in combination with abnormalities in cerebral blood flow regulation have been implicated in the genesis of PIVH in the newborn animal model $(31,32)$.

In summary, the present study suggests that indomethacin decreases cerebral blood flow and enhances the autoregulatory ability of the cerebral vascular bed of the newborn lamb at increasing cerebral perfusion pressure. We speculate that the mechanism by which this drug reduces the risk for severe PIVH is by effectively preventing high cerebral blood flow values during periods of increased cerebral perfusion pressures. Such periods often occur during and immediately after birth asphyxia and/or during hypercarbia-induced vasodilation of the resistance vessels of the cerebral vascular bed. The effects of indomethacin on cerebral perfusion and autoregulation during cerebral perfusion pressures lower than $40 \mathrm{~mm} \mathrm{Hg}$ were not investigated in this study and remain to be determined. A negative effect of indomethacin on cerebral blood flow and metabolism at lower perfusion pressures may possibly counteract its beneficial influence on autoregulatory ability of the cerebral vascular bed at high cerebral perfusion pressures.

\section{REFERENCES}

1. Papile LA, Munsick-Bruno G, Schaefer A 1983 Relationship of cerebral intraventricular hemorrhage and early childhood neurologic handicaps. J Pediatr 103:273-276

2. Ford LM, Steichen J, Steichen Asch PA, Babcock D. Fogelson MH 1989 Neurologic status and intracranial hemorrhage in very-low-birth-weight preterm infants: outcome at 1 year and 5 years. Am J Dis Child 143:1186-1190

3. Hutchison AA, Ogletree ML, Palang JH 1985 Plasma 6-keto prostaglandin F and thromboxane B2 concentrations in preterm neonates during the first three postnatal days: association with intracranial hemorrhage, the idiopathic respiratory distress syndrome and patent ductus arteriosus. Prostaglandins Leukotrienes Med 18:163-181

4. Rennie JM. Dole J, Cooke RWI 1987 Elevated levels of immunoreactive prostacyclin metabolites in babies who develop intraventricular hemorthage. Acta Paediatr Scand 76:19-23

5. Ment LR, Duncan CC, Ehrenkranz RA, Kleinman CS, Pitt BR. Taylor KJW, Scott DT. Stewart WB. Gettner P 1985 Randomized indomethacin trial for prevention of intraventricular hemorrhage in very low birth weight infants. J Pediatr 107:937-943

6. Hanigan WC, Kennedy G, Roemisch F, Anderson R, Cusack T, Powers W 1988 Administration of indomethacin for the prevention of periventricular intraventricular hemorrhage in high-risk neonates. J Pediatr 112:941-947

7. Setzer Bandstra E, Montalvo BM. Goldberg RN, Pacheco I, Ferrer PL, Flynn J, Gregorios JB, Bancalari E 1988 Prophylactic indomethacin for prevention of intraventricular hemorrhage in premature infants. Pediatrics 82:533-542

8. Ment LR, Duncan CC, Ehrenkranz RA, Kleinman CS, Taylor KJW, Scot DT. Gettner P. Sherwonit E. Williams J 1988 Randomized low-dose indomethacin trial for prevention of intraventricular hemorrhage in very low birth weight neonates. J Pediatr 112:948-955

9. Bada HS, Green RS, Pourcyrous M, Leffler CW, Korones SB, Magill HL Arheart K. Fitch CW, Anderson GD, Somes G, Tullis K, Campbell J 1989 Indomethacin reduces the risk of severe intraventricular hemorrhage. J Pediatr 115:631-637

10. Leffler CW. Busija DW, Beasley DG 1987 Effect of therapeutic dose of indomethacin on the cerebral circulation of newborn pigs. Pediatr Res $21: 188-192$

11. Wennmalm A, Erikson S, Wahren J 1981 Effect of indomethacin on basal and carbon dioxide stimulated cerebral blood flow in man. Clin Physiol 1:227234

12. De Giulio PA, Cameron CF, Mishra OP, Delivoria-Papadopoulos M, Wagerle LC 1990 Differential effect of ibuprofen and indomethacin on cortical prostanoids and pial arteriolar diameter during hypercapnia in newborn piglets. Pediatr Res 27:233A(abstr)

13. Chemtob S. Beharry K. Barna T, Aranda JV 1990 Ibuprofen does not compromise ileal and renal hemodynamics in the newborn piglet. Pediatr Res 27:57A(abstr)

14. Sonesson SE, Herin P 1988 Intracranial arterial blood flow velocity and brain blood flow during hypocapnia and hypercarbia in newborn lambs: a validation of range-gated Doppler ultrasound flow velocimetry. Pediatr Res 24:423-426

15. Purves MJ, James IM 1959 Observations on the control of cerebral blood flow in the sheep fetus and newborn lamb. Circ Res 25:651-667

16. Szymonowicz W, Walker AM, Yu VY. Stewart ML. Cannata J, Cussen L 1990 Regional cerebral blood flow after hemorrhagic hypotension in the preterm. near-term, and newborn lamb. Pediatr Res 28:361-366

17. Orr GW. Green HJ. Hughson RL, Bennett GW 1982 A complete linear regression model to determine ventilatory anaerobic threshold. J Appl Physiol 52:1347-1352

18. Slinker BK. Glantz SA 1990 Missing data in two-way analysis of variance. Am J Physiol 258:R291-R298

19. Taylor GA. Short BL, Walker LK. Traystman RJ 1990 Intracranial blood flow: quantification with duplex Doppler and color Doppler flow US. Radiology 176:231-236

20. Greenberg JH, Noordergraaf A, Reivich M 1978 Control of cerebral blood flow. In: Baan J, Noordergraaf A, Raines L (eds) Cardiovascular System Dynamics: Models and Experiments. MIT Press, Cambridge, MA, pp 391 398

21. Lundell BPW, Kennedy KA, Lindstrom DP. Sundell H, Stahlman MT 1986 Intracranial Doppler flow velocimetry compared with extra cranial carotid flow measurements. Acta Paediatr Scand 329:127-133

22. Kilbom A Wennwalm A 1976 Endogenous prostaglandins as local regulators of blood flow in man: effect of indomethacin on reactive and functional hyperemia. J Physiol 257:109-121

23. Bill A 1979 Effects of indomethacin on regional blood flow in conscious rabbits: a microsphere study. Acta Physiol Scand 105:437-444

24. Leffler CW, Busija DW, Beasley DG, Fletcher AM, Green RS 1986 Effects of indomethacin on cardiac output distribution in normal and asphyxiated piglets. Prostaglandins 31:183-190

25. Trevor AJ, Miller RD 1987 General anesthetics. In: Katzung BG (ed) Basic and Clinical Pharmacology. Appleton \& Lange. Los Altos, CA, pp 279-288

26. van Bel F, van de Bor M. Stijnen T, Baan J, Ruys JH 1987 The etiological role of cerebral blood flow alterations in the development and extension of peri-intraventricular haemorrhage. Dev Med Child Neurol 19:601-614

27. Lou HC, Lassen NA. Friis-Hansen B 1979 Impaired autoregulation of cerebra blood flow in the distressed newborn infant. J Pediatr 94:118-121

28. Baerts W. Fetter WPF. Hop WCJ, Wallenburg HCS, Spritzer R, Sauer PJJ 1990 Cerebral lesions in preterm infants after tocolytic indomethacin. Dev Med Child Neurol 32:910-918

29. Wei EP, Kontos HA. Dietrich WD. Poulishock JT. Ellis EF 1981 Inhibition by free radical scavengers and by cyclooxygenase inhibitors of pial arteriolar abnormalities from concussive brain injury in cats. Circ Res 48:95-103

30. Pourcyrous M. Busija DW, Leffler CW. Bada HS, Korones SB 1991 Therapeutic dose of indomethacin inhibits superoxide anion generation during asphyxia/reventilation in newborn pigs. Pediatr Res 29:230A(abstr)

31. Ment LR, Stewart WB. Duncan CC 1985 Beagle puppy model of intraventricular hemorrhage: effect of superoxide dismutase on cerebral blood flow and prostaglandins. J Neurosurg 62:563-569

32. Rosenberg AA, Murdaugh E. White CW 1989 The role of oxygen-free radicals in postasphyxia cerebral hypoperfusion in newborn lambs. Pediatr Res 26:215-219 